\title{
Kidney protective potential of lactoferrin: pharmacological insights and therapeutic advances
}

\author{
Md. Sarwar Zahan', Kazi Ahsan Ahmed' ${ }^{1}$, Akhi Moni ${ }^{1}$, Alessandra Sinopoli ${ }^{2,3}$, Hunjoo Ha ${ }^{4}$, and Md Jamal Uddin ${ }^{1,4, *}$ \\ ${ }^{1}$ ABEx Bio-Research Center, Dhaka 1230, Bangladesh, ${ }^{2}$ Department of Prevention, Local Health Unit Roma 1, Rome 00185, ${ }^{3}$ Department of Experimental Medi- \\ cine, University of Rome Tor Vergata, Rome 00185, Italy, ${ }^{4}$ Graduate School of Pharmaceutical Sciences, Ewha Womans University College of Pharmacy, Seoul \\ 03760, Korea
}

\author{
ARTICLE INFO \\ Received October 28, 2021 \\ Revised November 29, 2021 \\ Accepted November 30, 2021 \\ *Correspondence \\ Md Jamal Uddin \\ E-mail: hasan800920@gmail.com
}

\section{Key Words}

Drug development

Kidney disease

Lactoferrin

Pharmacology

Therapeutics

\begin{abstract}
Kidney disease is becoming a global public health issue. Acute kidney injury (AKI) and chronic kidney disease (CKD) have serious adverse health outcomes. However, there is no effective therapy to treat these diseases. Lactoferrin (LF), a multi-functional glycoprotein, is protective against various pathophysiological conditions in various disease models. LF shows protective effects against AKI and CKD. LF reduces markers related to inflammation, oxidative stress, apoptosis, and kidney fibrosis, and induces autophagy and mitochondrial biogenesis in the kidney. Although there are no clinical trials of LF to treat kidney disease, several clinical trials and studies on LF-based drug development are ongoing. In this review, we discussed the possible kidney protective mechanisms of LF, as well as the pharmacological and therapeutic advances. The evidence suggests that LF may become a potent pharmacological agent to treat kidney diseases.
\end{abstract}

\section{INTRODUCTION}

Noncommunicable diseases (heart disease, diabetes, or kidney disease) have replaced communicable diseases (influenza, malaria, or AIDS) as the most common causes of premature death worldwide [1]. In particular, kidney disease is a global public health problem, affecting over 750 million persons worldwide [2]. The burden of kidney disease varies significantly across the world. While the magnitude of the impact is better defined in developed countries, recent evidence suggests developing countries have a similar or even greater kidney disease burden [3].

Acute kidney injury (AKI) and chronic kidney disease (CKD) are common in hospitalized patients. Patients who survive AKI are at a higher risk of CKD [4]. CKD development increases the risk of mortality and results in end-stage kidney disease [5]. Globally, the total number of people with CKD, AKI, and kidney replacement therapy has exceeded 850 million. Monitoring the severity of this disease will be beneficial for developing therapeutic approaches [6]. Existing treatment strategies may not restrain kidney failure [6-8]. Therefore, a promising therapeutic candidate must be identified to preserve kidney function.

Lactoferrin (LF) is a non-heme iron-binding glycoprotein. It is a transferrin family member, and it is found in breast milk as well as in other exocrine fluids [9]. Immune responses are required to protect vital organs like the kidney from different harmful conditions. A study has identified LF as a crucial factor in facilitating innate and adaptive immune responses [10]. LF possesses multiple pharmacological properties, such as anti-bacterial, anti-fungal, anti-viral, anti-inflammatory, and antioxidative, mediated by multiple receptors [11-15]. LF alleviates osteoporosis by improving bone growth and metabolic processes [16]. It plays a significant role in the fight against diabetes in rat models [17]. In some intestinal diseases, LF can be used as adjuvant therapy [18,19]. It shows a favorable response against human colorectal polyp growth (i) (5) This is an Open Access article distributed under the terms of the Creative Commons Attribution Non-Commercial License, which permits unrestricted non-commercial use, distribution, and reproduction in any medium, provided the original work is properly cited. Copyright $\odot$ Korean J Physiol Pharmacol, pISSN 1226-4512, elSSN 2093-3827
Author contributions: This work is a collaboration among all of the authors. M.J.U. and A.M. designed the outline. M.S.Z. and K.A.A. wrote the initial draft of the manuscript. M.S.Z. prepared the tables and illustrated the figures. M.J.U., A.M., H.H., and A.S. edited and reviewed the scientific contents described in the manuscript. All authors read and approved the final submitted version of the manuscript. 
$[19,20]$. Studies have shown that aerosolized LF protects against lung injury and fibrosis after moderate hyperoxia [19,21]. In our previous study, we have summarized the functions, pharmacological insights, and therapeutic promises of LF against various pathological conditions in general [22]. Also, we found multiple clinical trials on LF as a therapeutic agent for treating different diseases such as sepsis, anemia, diarrhea, Crohn's disease, sinusitis, AIDS, periodontal disorders, and so on [22]. Though there is almost no evidence on clinical trial of LF for treating kidney diseases like AKI and CKD, various preclinical studies have shown protective effect of LF against kidney diseases. For instances, LF shows antioxidant, anti-inflammatory, and anti-proliferative properties and protects the kidney against chromium-induced AKI in rats [11]. Recently, LF therapy was observed to restore kidney function and to protect against AKI and early kidney fibrosis [23].

Considering these findings together, we have hypothesized that LF may provide kidney protective functions against various pathologies in kidney cells and tissues. In this review, we have summarized the kidney protective potentiality of LF, the mechanisms involved, and the therapeutic advances.

\section{METHODS}

We performed a literature search of original research articles using PubMed, Scopus, and Google on the effects of LF against various pathophysiological disorders such as AKI and CKD. We conducted a search using various keywords, including LF, structure, receptors, inflammation, oxidative stress, fibrosis, endoplasmic reticulum stress (ER stress), autophagy dysfunction, mitochondrial dysfunction, clinical trials, and drug development.

\section{STRUCTURE AND RECEPTORS OF LACTOFERRIN}

In 1939, LF, a member of the transferrin family, was discovered in bovine milk [24,25]. LF consists of two globular lobes $(80 \mathrm{kDa}$ glycoprotein) of $\sim 700$ amino acids. The two globular lobes are connected by a flexible alpha helix [26]. There are three isoforms of LF, LF- $\alpha$ (only binds to iron), LF- $\beta$, and LF-g $[25,27]$. Human and bovine LF (bLF) structures are shown in Fig. 1.

LF mediates its biological activities through interaction with various receptors on multiple tissues and cell types, including intestinal epithelial cells and lymphocytes $[28,29]$. The LF receptors are CD14, low-density lipoprotein receptor-related protein-1 (LRP-1/CD91), intelectin-1 (omentin-1), toll-like receptor 2 and 4 (TLR4), transferrin binding receptors (TFR1, TFR2), and C-XC-motif cytokine receptor 4 (CXCR4) [30-34]. LF binds to cellsurface and extracellular matrix macromolecules such as heparan sulfate proteoglycans [35,36]. LF interacts with sulfated proteoglycans at the cell surface and then binds specifically with membrane receptors to stimulate ERK1/2 and PI3K/Akt pathways in the cells. Because of the high metabolic rate of cancer cells, their expression of surface receptors is generally increased [37,38]. LFconjugated $\mathrm{N}$-trimethylated chitosan nano particles (NPs) show higher cellular uptake by 16HBE and SH-SY5Y cells [39]. Intelectin-1 (omentin-1), another receptor, is expressed in intestinal epithelia [40]. Iron absorption receptors such as divalent metal ion receptor (DMT1) are also expressed in intestinal cells [41]. LF binds to TLR4 to activate nuclear factor kappa B (NF- $\mathrm{KB}$ ) and CXCR4 [30,42].

B

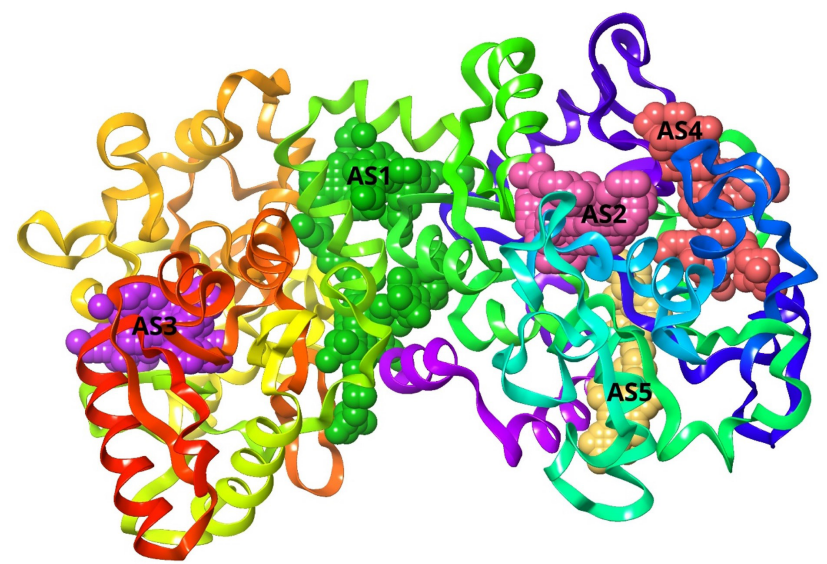

Fig. 1. Crystal structures of ( $A$ ) bovine lactoferrin (bLF, PDB code = 1BLF), and (B) human lactoferrin (1LFG). AS1, AS2, AS3, AS4, and AS5 indicate the active sites of LF. 

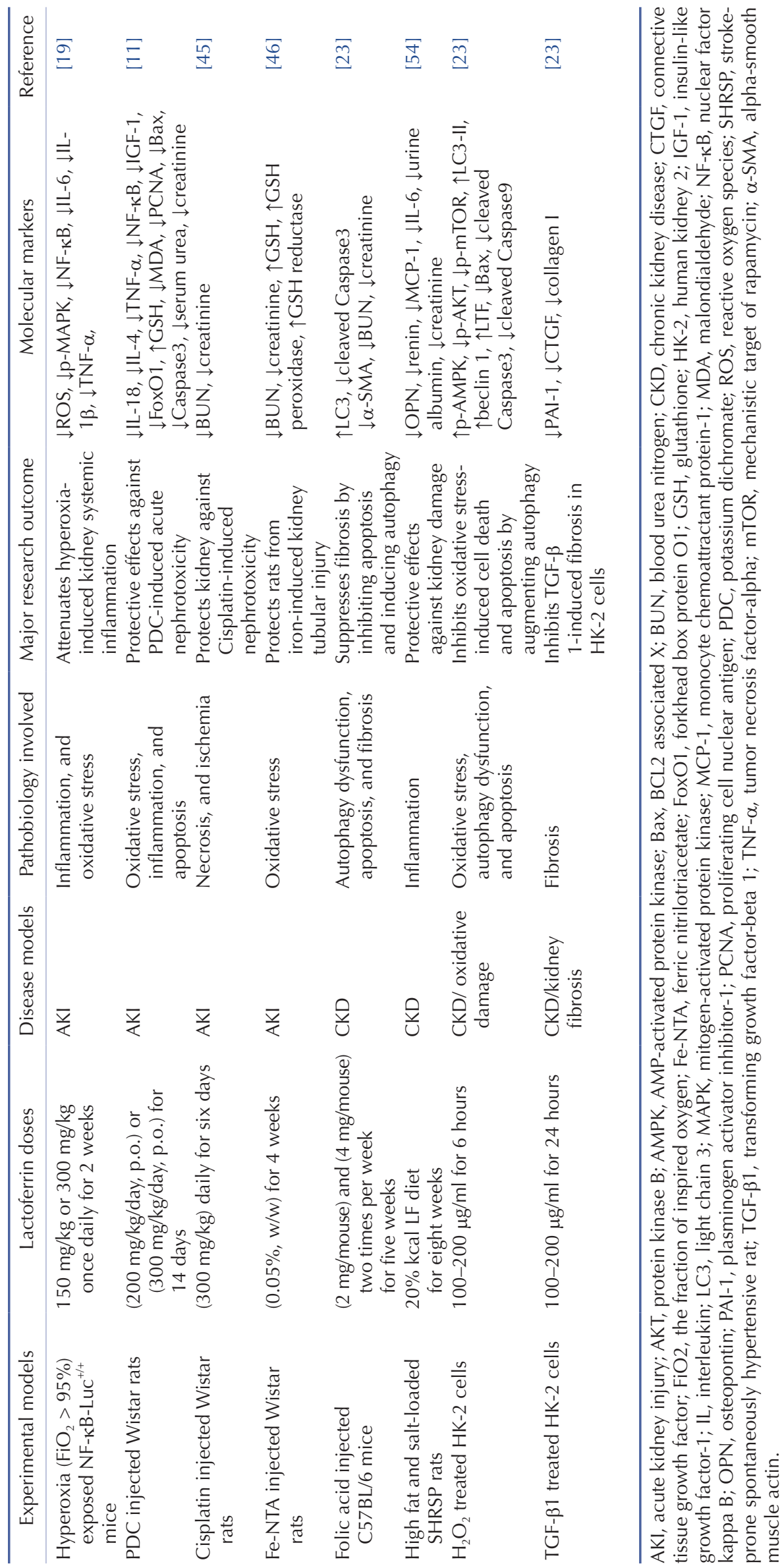


\section{PROTECTIVE EFFECTS OF LACTOFERRIN AGAINST KIDNEY DISEASES}

We first summarize the data demonstrating the protective mechanisms of LF against AKI and CKD (Table 1, Figs. 2 and 3).

\section{Acute kidney injury}

AKI occurs suddenly and causes a rapid increase in serum creatinine, decreases in urine output, or both [43]. The leading inducers of AKI are ischemia, hypoxia, and nephrotoxicity [44]. LF prevents ischemia, hyperoxia, and nephrotoxicity-induced AKI in rats and mice models.

LF showed kidney protective effects against potassium dichro- mate (PDC)-induced AKI in rats [11]. Pretreatment with LF significantly reduced PDC-induced tubular epithelial hyperplasia, inflammation, oxidative stress, and apoptosis. Also, LF restored PDC-induced serum urea and creatinine; restored the glutathione (GSH) and malondialdehyde level; normalized insulin-like growth factor-1 and interleukin (IL)-18 expression; and decreased the level of apoptosis-related biomarkers Bax and caspase- 3 in AKI rats [11]. The chemotherapeutic agent cisplatin has a nephrotoxic effect in AKI. Pretreatment with bLF significantly reduced cisplatin-induced nephrotoxicity and impairment of the proximal tubules by attenuating tubular necrosis in rats [45]. Lower levels of platinum content, blood urea nitrogen (BUN), and creatinine were observed in cisplatin-injected rats treated with LF [45]. A hyperoxic condition $\left(\mathrm{FiO}_{2}>95 \%\right)$ causes massive reactive oxygen

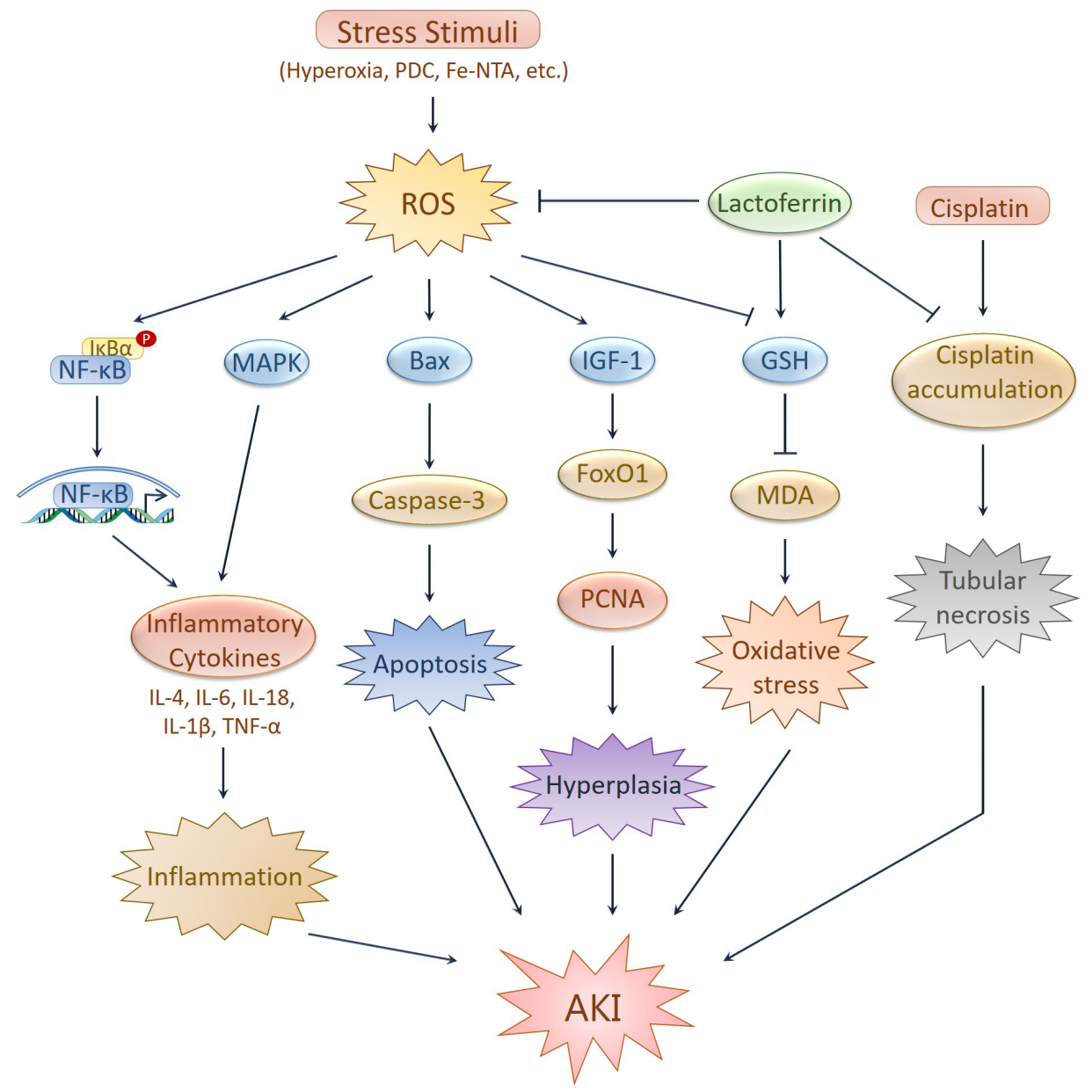

Fig. 2. Mechanisms of lactoferrin (LF) against AKI. Hyperoxia $\left(\mathrm{FiO}_{2}>95 \%\right)$ induces inflammation via ROS generation, MAPK and NF- $\kappa \mathrm{B}$ activation. LF inhibits inflammation by reducing ROS generation and downregulating pro-inflammatory cytokines. PDC significantly increases NF- $\kappa \mathrm{B}$, IL-18, IL4, and IGF-1 accompanied by kidney MDA and decreased GSH. Increased IL-4 leads to TNF- $\alpha$ expression and inflammation. IGF-1 enhances FoxO1 production, leading to tubular epithelial hyperplasia. Increased MDA leads to oxidative stress. PDC also increases Bax and caspase-3, resulting in apoptosis. LF prevents AKI by inhibiting PDC-induced inflammation, hyperplasia, apoptosis, and oxidative stress. Fe-NTA lowers the GSH content that causes oxidative stress. LF normalizes GSH and inhibits oxidative stress. Also, cisplatin causes cisplatin accumulation in the kidney that leads to tubular necrosis. LF decreases platinum content in the kidney, prevents cisplatin accumulation and inhibits tubular injury. AKl, acute kidney injury; Bax, BCL2 associated X; Fe-NTA, ferric nitrilotriacetate; $\mathrm{FiO}_{2}$, the fraction of inspired oxygen; FoxO1, forkhead box protein O1; GSH, glutathione; IGF-1, insulinlike growth factor-1; IL, interleukin; MDA, malondialdehyde; NF- $\mathrm{B}$, nuclear factor kappa B; PCNA, proliferating cell nuclear antigen; PDC, potassium dichromate; TNF- $\alpha$, tumor necrosis factor alpha; MAPK, mitogen-activated protein kinase; ROS, reactive oxygen species. 


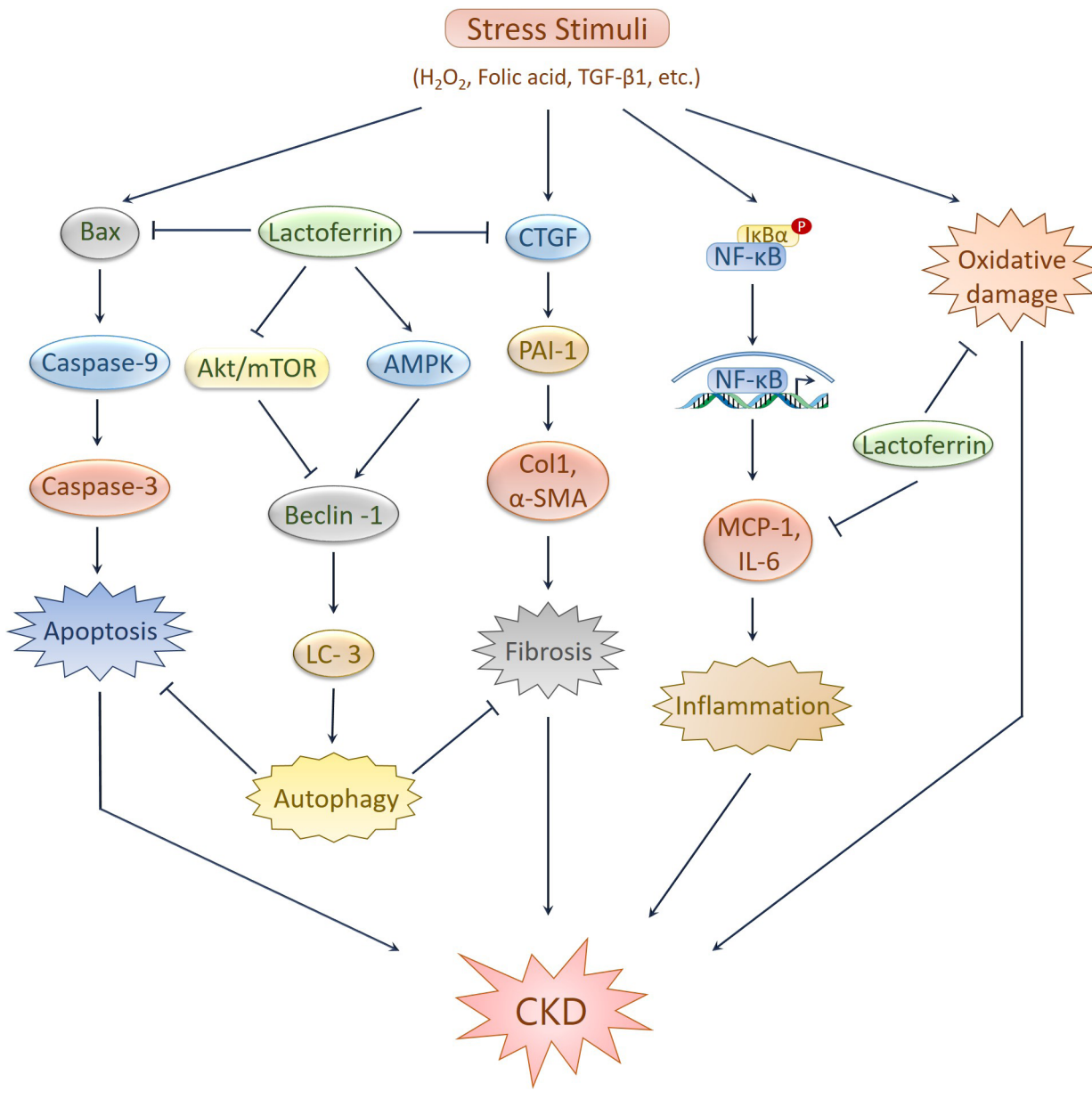

Fig. 3. Mechanisms of lactoferrin (LF) against CKD. LF induces autophagy by activating AMPK and inhibiting the Akt/mTOR pathway. Hydrogen peroxide $\left(\mathrm{H}_{2} \mathrm{O}_{2}\right)$ causes oxidative stress-induced cell death and apoptosis. LF inhibits cell death and apoptosis by augmenting autophagy and reducing caspase- 3 . Folic acid induces kidney fibrosis, and LF prevents that by inhibiting apoptosis and inducing autophagy. TGF- $\beta 1$ induces fibrosis by increasing the expression of PAI-1, CTGF, and collagen-1, and LF inhibits fibrosis by decreasing their expression. A high fat and salt condition promotes inflammation leading to kidney damage. LF inhibits inflammation and protects against kidney damage by reducing inflammatory cytokines. AKT, protein kinase B; AMPK, AMP-activated protein kinase; Bax, BCL2 associated X; CKD, chronic kidney disease; Col1, collagen 1; CTGF, connective tissue growth factor; IL, interleukin; LC3, light chain 3; MCP-1, monocyte chemoattractant protein-1; mTOR, mechanistic target of rapamycin; $\mathrm{PAl}-1$, plasminogen activator inhibitor-1; TGF- $\beta 1$, transforming growth factor beta $1 ; \alpha$-SMA, alpha-smooth muscle actin. species (ROS) production and leads to systemic inflammation in mice [19]. Oral administration of bLF alleviated the hyperoxiainduced oxidative stress and inflammation by reducing ROS generation and mitogen-activated protein kinase, and NF- $\mathrm{B}$ activation in a transgenic mouse $\left(\mathrm{NF}-\kappa \mathrm{B}-\mathrm{Luc}^{+/+}\right)$model [19]. Subsequently, it reduced the expression of pro-inflammatory cytokines IL-6 and IL-1 $\beta$, and tumor necrosis factor alpha (TNF $\alpha$ ) [19]. It has also been observed that bLF can protect the kidney against iron-induced oxidative damage and kidney tubular injury [46]. In ferric nitrilotriacetate (Fe-NTA)-injected rats, pretreatment with bLF reduced BUN and the creatinine levels that Fe-NTA elevated. Also, bLF suppressed Fe-NTA-induced oxidative damage and increased the expression of antioxidant enzymes, e.g., GSH peroxidase and GSH reductase, in the kidneys [46].

Moreover, camel milk showed kidney protective effects against 5-fluorouracil-induced kidney injury in the Wistar rat model [47]. The abundance of LF content in camel milk played a significant role in protecting the kidney against 5-fluorouracil-induced inflammation and oxidative damage [47]. LF also attenuated acute alcoholic liver injury by improving redox-stress response capacity in mice [48].

Ammendolia et al. [49] observed the anti-herpetic effect of bLF in green monkey kidney cells. LF blocked the entry of herpes simplex virus type-1 by competing with heparan sulfate receptor and inhibiting cell to cell spreading [49]. In a mouse model of choroidal neovascularization, LF inhibited hypoxia-inducible factor [50]. In addition, it protected the corneal epithelial cell line from hypoxic induced cell damage and protected immature hypoxic-ischemic rat brain [51,52]. However, further study is required to determine whether LF can protect the kidney from hypoxia-induced cell damage.

\section{Chronic kidney disease}

CKD is a heterogeneous disorder that gradually affects kidney functions and structure. CKD is defined as kidney damage and a low glomerular filtration rate $\left(<60 \mathrm{ml} / \mathrm{min} / 1.73 \mathrm{~m}^{2}\right)$ for three months or more [53].

LF prevented the AKI to CKD transition in the folic acid injected mice model [23]. LF normalized folic acid-induced BUN and creatinine levels. LF inhibited folic acid-induced oxidative stress, fibrosis, and apoptosis of kidney cells [23]. Also, LF showed an antifibrotic role by augmenting autophagy, which involves activation of AMP-activated protein kinase (AMPK) and inhibition of the Akt/mTOR pathway [23]. Another study showed that an LF-rich diet protected the kidney against inflammation and kid- 
ney damage in high fat and salt-loaded rats [54]. An LF enriched diet lowered the nephritis score and the albumin to creatinine ratio. It reduced the expression of the kidney damage markers osteopontin and renin, and the inflammatory markers monocyte chemoattractant protein-1 and IL-6 [54].

Hydrogen peroxide $\left(\mathrm{H}_{2} \mathrm{O}_{2}\right)$ treatment induces oxidative stress and apoptosis in human kidney proximal tubular epithelial (HK2) cells [23]. Pretreatment with LF suppressed cellular oxidative stress and apoptosis by augmenting autophagy, which involves activation of AMPK and the Akt/mTOR pathway inhibition. Besides, it increased the expression of the autophagy-related gene beclin-1 and suppressed the apoptosis-related genes Bax, cleaved caspase-3, and cleaved caspase-9 [23]. In a similar study, LF inhibited fibrosis in transforming growth factor- $\beta 1$ (TGF- $\beta 1$ )treated HK-2 cells by suppressing the expression of TGF- $\beta 1$ target genes plasminogen activator inhibitor-1 (PAI-1), connective tissue growth factor (CTGF), and collagen-1 [23].

\section{PHARMACOLOGICAL POTENTIALS OF LACTOFERRIN AGAINST VARIOUS PATHOPHYSIOLOGICAL CONDITIONS IN KIDNEY DISEASES}

A recent study has reviewed the protective effects of LF against various pathological conditions [22]. The following sections summarize the current knowledge of LF in mediating protection against kidney disorders-associated pathological conditions, including oxidative stress, inflammation, fibrosis, ER stress, autophagy dysfunction, and mitochondrial dysfunction (Table 1, Figs. 1 and 2).

\section{Oxidative stress}

Oxidative stress can be defined as an imbalance between prooxidants and antioxidants. It represents the imbalance of redox signaling [55-60]. Free radicals are mostly formed as a by-product of aerobic metabolism $[61,62]$. Free radicals can positively or negatively affect the human body [63]. ROS is mainly formed in mitochondria during oxygen metabolism [55]. ROS includes superoxide anions, $\mathrm{H}_{2} \mathrm{O}_{2}$, and hydroxyl radicals [62]. ROS can induce several pathologic conditions by causing damage to DNA and proteins, promoting lipid peroxidation, and triggering cell death $[62,64,65]$. Also, oxidative stress plays a vital role in the pathophysiology of various kidney diseases [61,66]. The most common consequence of oxidative stress is inflammation, which is associated with kidney diseases. Generally, oxidative stress is associated with AKI and CKD development [67]. Oxidative stress and inflammation are commonly seen in CKD patients [68]. It has been shown that an impaired mitochondrial respiratory system contributes to high oxidative stress in CKD patients [69]. ROS can play a significant role in diabetic nephropathy and immune-mediated glomerulonephritis. ROS mediates kidney cell injury through triggering signal transduction cascades and the activation of transcription factors that upregulate kidney cell injury-associated genes and proteins [62]. Besides, smoking and alcohol consumption also contribute to kidney oxidative stress [61]. Excessive ROS production may increase the risk of morbidity and mortality in CKD patients [55]. Severe oxidative damage may cause the failure of organ repair or replacement systems [58]. Protection by complex antioxidants is required to prevent this oxidative stress-induced injury $[62,63]$.

LF acts as an antioxidant, which is the principal component of immune homeostasis. LF may decrease intracellular ROS levels and oxidative stress-induced apoptosis. Transitional metals such as iron are the leading cause of oxidative stress, which control ROS production. LF can inhibit lipid peroxidation due to iron sequestration [10]. Administration of bLF protects kidney tissue from Fe-NTA-induced kidney tubular oxidative injury in rat models. It appears that bLF suppresses serum markers of acute kidney failure and kidney tubular injury. These results indicate that LF ingestion effectively prevents kidney tubular oxidative damage [46]. LF diminishes $\mathrm{H}_{2} \mathrm{O}_{2}$-induced apoptosis in HK-2 cells by inducing autophagy [23]. Also, LF mediates the first-line immune defense and controls oxidative cellular activity [70].

\section{Inflammation}

Inflammation is a complicated interaction that combines many physiological and pathological processes [71,72]. Adaptive inflammatory reactions in tissue occur in response to harmful stimuli and situations such as infectious, ischemic, toxic, or autoimmune injuries [71-73]. Inflammation persists in all kinds of kidney diseases. Inflammasomes are macromolecules that can activate inflammatory responses, and they are involved in kidney diseases [74]. In AKI, several factors such as leukocytes, adhesion molecules, chemokines, and cytokines induce inflammation [11]. Pro-inflammatory cytokines, including IL-18 and TNF $\alpha$, play significant inflammatory roles in kidney diseases $[11,75]$. Activation of the transcription factor NF- $\mathrm{KB}$ stimulates pro-inflammatory gene expression in kidney tissue injury [76]. Kidney inflammation and its implications have inspired researchers to find novel therapeutics [77].

LF from various sources (human, bovine, porcine, caprine, camelid, and buffalo) has been used successfully against the inflammatory processes [78]. LF can contribute to the immune system of the kidneys through iron metabolism [79]. LF can reduce the damage of excessive inflammatory responses by sequestering free iron and directing reactive oxygen intermediates [19]. It may be a part of the antioxidant defense system that protects the kidneys from nonmicrobial oxidative damage, i.e., ischemia and reperfusion [79]. LF inhibited inflammation in the chromium-induced AKI model by downregulating IL-18 and other inflammatory cytokines [23]. Previous studies have shown that oral adminis- 
tration of LF can effectively reduce hyperoxia-mediated kidney inflammation and kidney injury in mice models [19]. In addition, LF plays a significant role in controlling immune responses by activating various signaling pathways that protect against acute and chronic inflammation in kidneys [80].

\section{Fibrosis}

Kidney fibrosis is the formation of scars in the parenchyma and it is the common phenotype of almost all chronic and progressive nephropathies [81]. Nearly all types of CKD involve excessive accumulation and deposition of extracellular matrix components that results in kidney fibrosis $[82,83]$. Kidney fibrosis is mainly characterized by glomerulosclerosis and tubulointerstitial fibrosis $[82,84]$. Inflammation of the tubulointerstitial compartment is considered the leading cause of kidney fibrosis [85]. Some cellular pathways like mesangial and fibroblast activation and tubular epithelial-mesenchymal transition (EMT) have been recognized as the main ways to stimulate matrix-producing cells in diseased conditions. TGF- $\beta 1$ is a fibrotic factor that plays a vital role in kidney fibrosis. It is considered the critical modulator in regulating the EMT process via the SMAD pathway, possibly in association with hypoxia-inducible factors $[82,86]$. Defective matrix degradation can lead to tissue scarring, but the proper function and mechanisms of the matrix-degrading enzymes in the injured kidney gradually become complicated [82]. During progressive kidney injury, TLR2 activation may trigger kidney inflammation. However, the absence of TLR2 does not affect the progression of kidney interstitial fibrosis. In patients with IgA nephropathy, TLR2 expression is upregulated in tubulointerstitial cells (myofibroblasts and macrophages) [87]. Almost all types of cells (such as fibroblasts, tubular epithelial cells, pericytes, endothelial cells, vascular smooth muscle cells, mesangial cells, and podocytes) in the kidney along with the infiltrated cells (such as lymphocytes, macrophages, and fibrocytes) and conditions like hypertension, hypoxia, hyperglycemia, and proteinuria, are involved in the pathogenesis of kidney fibrosis $[84,88]$. Kidney fibrosis is a progressive process that eventually leads to end-stage kidney failure, which requires dialysis or kidney transplantation [82].

LF plays an antifibrotic role in human kidney tubular cells. LF can prevent TGF- $\beta 1$-induced kidney fibrosis in HK-2 cells. LF downregulates the expression of TGF- $\beta 1$ target genes, i.e., PAI- 1 , CTGF and collagen-1 [23]. Thus, LF may show kidney protective effects against the folic acid-induced AKI to CKD transition in a mouse model [23]. Treatment with LF restored kidney function and prevented kidney fibrosis by inhibiting apoptosis and augmenting autophagy [23].

\section{Autophagy dysfunction}

Autophagy is an intracellular system that degrades and recycles cytoplasmic components [89] and long-lived proteins within the lysosome [90]. Apart from being a cell death apparatus, it plays a significant role in the homeostasis of cells, tissues, and organisms [91]. Excessive autophagy induction or blockade of autophagy flux causes autophagy dysfunction [92]. It can be associated with various diseases like cancer development and progression [93], Crohn's disease [94], neurodegenerative diseases like Parkinson's disease [95], and Alzheimer's disease [96]. Autophagy protects the kidney from AKI by inhibiting proximal tubule degradation, acute ischemic injury [97], and cisplatin-induced nephrotoxicity [98]. Autophagy dysfunction is associated with diabetic nephropathy [99] and chronic kidney disease [100,101]. In podocytes, it is involved in age-related chronic kidney disease [102].

In $\mathrm{H}_{2} \mathrm{O}_{2}$ treated $\mathrm{HK}-2$ cells and folic acid-injected mice, LF inhibited kidney disease by augmenting autophagy. LF induces autophagy by activating AMPK and inhibiting the Akt/mTOR pathway [23]. It can increase autophagy via AMPK activation through the LRP-1 receptor [103]. LF also can induce neighbor of Brcal-mediated autophagy [104].

\section{Mitochondrial dysfunction}

Mitochondria are the powerhouses of cells that generate energy as an adenosine triphosphate molecule [105]. Mitochondrial dysfunction is the failure of mitochondria to perform appropriately and is characterized by electron transport chain deficiency and reduced high-energy molecule synthesis [106]. It is associated with a broad range of diseases such as type-2 diabetes [107], insulin resistance [108], atherosclerosis [109], neurodegenerative diseases [110], cardiovascular disease [111], cancer [112], and liver disease [113]. Mitochondrial dysfunction is the leading cause of $\mathrm{AKI}$ and CKD. Impairment of mitochondria can cause excessive ROS and reactive nitrogen species production, leading to oxidative stress of the kidney [114]. Disturbance of mitochondrial homeostasis in the kidney leads to inflammation [115], fibrosis, and kidney injury [116]. Mitochondrial dysfunction is also associated with the AKI-to-CKD transition [117], diabetic kidney disease [118], glomerulosclerosis and progressive kidney failure [119], and inherited kidney disease [120].

LF might prevent mitochondrial dysfunction in the kidney by reducing ROS production in mice [19]. LF decreased lipopolysaccharide-induced mitochondrial dysfunction and protected against oxidative stress in cultured cells in an endotoxemia model [96]. It also prevented mitochondrial dysfunction by decreasing ROS generation in neuronal cells [121].

\section{ER stress}

The endoplasmic reticulum is the site where membrane and secretory proteins are synthesized and folded [122]. Proteins are also modified and delivered to their destination from here. In mammalian cells, sterols and lipids are synthesized in the ER [123]. As it is essential for many cellular functions [124], any distur- 
bance of its functions can cause an imbalance in protein folding and secretory capability that causes the accumulation of unfolded proteins in the lumen, causing ER stress [123]. This condition activates the unfolded protein response, which is related to many inflammatory and stress signaling pathways [124]. If ER stress becomes severe, it can even cause cell death [125-127]. There is clear evidence of a link between ER stress and kidney disease. It promotes the development of AKI and CKD. ER stress is also involved in ischemia, ischemia-reperfusion, and acute nephrotoxicity associated with AKI [128]. It can cause glomerular and tubular damage in patients with AKI and CKD [129].

Recombinant human LF might be associated with the inhibition of ER stress in hepatocytes [9]. Raghavan et al. [130] reported that high glucose (HG) significantly increased the mRNA level of ER stress markers such as GRP78, CHOP, IRE1, and PERK, whereas only XBP1 rises transiently in pancreatic beta-cells. Interestingly, these were significantly reduced by treatment of LF. In mesenchymal stem cells, HG also significantly increased the mRNA level of GRP78, IRE1, and PERK, whereas only IRE1 and XBP1 rise transiently. LF treatment significantly decreased those ER stress markers except XBP1 [130]. Since, no study regarding LF against ER stress in kidney cells has been found, further study is required to check whether LF can protect the kidney against $\mathrm{ER}$ stress-induced cellular damage.

\section{UPDATES ON CLINICAL TRIALS}

In general, there are multiple clinical trials of LF as a therapeutic agent for treating different diseases such as sepsis, anemia, diarrhea, Crohn's disease, sinusitis, AIDS, periodontal disorders, and so on [22]. To date, we found no clinical trials of LF for treating kidney disease. However, Jonasch et al. [131] performed a phase-2 clinical trial of talactoferrin (a recombinant form of human LF) on adult patients with metastatic kidney cell carcinoma. In a non-randomized study, 40 patients participated, and they were orally administered talactoferrin at a dose of $1.5 \mathrm{~g}$ twice daily on a 12-week-on 2-week-off schedule. The primary outcome of this trial was an increased survival rate of 59\% at 14 weeks. Since LF has substantial kidney protective potential, more clinical trials should be performed to test its efficacy against kidney disease.

\section{LACTOFERRIN-BASED DRUG DEVELOPMENT}

Recent advances of LF-based nanocarriers as efficient platforms for the delivery of anti-parkinsonian, anti-Alzheimer, anti-viral drugs, immunomodulatory and bone engineering applications have been reported [132]. In guinea pigs, subcutaneous administration of bLF caused more passive cutaneous anaphylaxis than oral administration [133]. Thus, oral administration may be the safest method [45]. However, oral administration is also challenging because LF is poorly absorbed in the gastrointestinal tract (GIT), leading to reduced bioavailability. LF is partially degraded in the GIT, and the large fragments are resistant to degradation. This enzymatic degradation shortens the half-life of LF, resulting in inadequate delivery [132]. The enzymatic degradation and absorption barrier reduces LF's therapeutic effect [134]. In some cases, LF can cause toxicity, an inflammatory response [135], mitochondrial damage, and cellular necrosis [136].

Several modifications can be applied to improve LF's drug delivery, bioavailability, and in vivo stability. PEGylation (the covalent attachment of polyethylene glycol) of LF can enhance its therapeutic properties [137]. An LF conjugate 40k-PEG-bLF was prepared by conjugating $40-\mathrm{kDa}$ branched polyethylene glycol (PEG) with bLF. This conjugate possesses an increased proteolytic half-life (at least 6-fold) and an increased plasma halflife (8.7-fold) compared to unmodified LF [138]. Another conjugate 20k-PEG-bLF was developed by conjugating $20-\mathrm{kDa}$ with bLF. This conjugate showed an increased proteolytic half-life (2 fold), a prolonged serum half-life (approximately 5.4 fold), and increased absorption from the intestinal tract (approximately 10 fold) in rats compared to unmodified LF [139]. Another method, liposomalization (encapsulation into liposome) of LF, exhibited an enhanced anti-inflammatory effect. bLF was encapsulated into a liposome consisting of egg yolk phosphatidylcholine and phytosterol. This liposomal-LF showed a more suppressive effect against carbon tetrachloride induced hepatic injury in rats than unmodified LF. It also exhibited improved anti-inflammatory action and increased intestinal absorption [133]. Liposomes can also be a significant carrier of LF in the treatment of arthritic and other inflammatory diseases. Positively charged liposomes are appropriate in the modification of LF's pharmacodynamics profile [140]. Liposomalization of LF can also enhance its antitumoral effects [141]. Several chitosan microparticles containing LF were prepared by a w/o emulsification-solvent evaporation method; among them, Ch- $\mathrm{LF}(\mathrm{N})$ is more effective. These microparticles showed gradual drug release properties and effective delivery to the intestinal tract [142]. Chitosan/alginate/calcium complex microparticles containing LF at a high loading were prepared to increase the efficacy and overcome LF's gastric digestion. These microparticles promoted the effectiveness of LF after oral administration by controlling the release of LF. It took $1 \mathrm{~h}$ to release around $60 \%$ of LF and $7 \mathrm{~h}$ to release up to $80 \%$ at pH 1.2 [143]. Chitosan solution coated alginate/calcium complex microparticles can also play a significant role in LF's intestinal delivery [144]. NPs are also used to develop LF as an active therapeutic. Ironsaturated bLF was adsorbed onto calcium phosphate nanocrystals (NCs), followed by coating with chitosan and further encapsulation in alginate [132]. The NCs induced apoptosis by downregulating survivin in cancer cells and cancer stem cells, inhibited angiogenesis and stem cell markers in the colon cancer model [37]. It also reduced tumor growth, was internalized in breast cancer, 
and induced apoptosis [41]. Nanoencapsulation of camel milk LF through alginate nanocapsules kept the LF intact in the stomach and safely delivered it to the lower GIT [145]. Nanoencapsulation within lipid nanovesicles also improved the efficacy of bLF [146]. These techniques can be applied to develop LF-based effective kidney protective therapeutics.

\section{CONCLUSIONS}

While kidney failure is becoming a global public health concern, there is no effective therapy that can treat or prevent kidney diseases. Our review suggests that LF may protect the kidney from both $\mathrm{AKI}$ and $\mathrm{CKD}$ as shown in in vitro and in vivo studies. In particular, LF prevents AKI in different models by inhibiting hyperoxia-induced systemic inflammation, cisplatin-induced nephrotoxicity, and iron-induced oxidative damage. LF also prevents PDC-induced AKI in rats by inhibiting hyperplasia, inflammation, oxidative stress, and apoptosis. On the other hand, LF prevents CKD development in the folic acid mice model. LFinduced autophagy plays a significant role in preventing CKD development by inhibiting fibrosis, oxidative stress, and apoptosis. Also, an LF-enriched diet protects against kidney damage in rats by reducing inflammation and kidney injury markers. Although LF has substantial kidney protective potentiality, LF has some limitations, such as poor enzymatic digestion and lower bioavailability, which can hinder its efficacy [132]. A pre-developed drug delivery system can be applied, or a new method could be developed for LF-based kidney protective drug development. Since recombinant human $\mathrm{LF}$ has been suggested as a valuable protein for pharmaceutical uses $[9,147]$, it can be another key for overcoming those limitations in treating kidney diseases. Also, this review highlights the lack of clinical studies testing LF as a kidney protective drug.

\section{FUNDING}

This work was funded by the National Research Foundation (No. 2020R1I1A1A01072879 and 2015H1D3A1062189) and the Brain Pool program was funded by the Ministry of Science and ICT through the National Research Foundation (No. 2020H1D3A2A02110924), Republic of Korea.

\section{ACKNOWLEDGEMENTS}

The authors acknowledge MD. Hasanur Rahman for his support in Fig. 1.

\section{CONFLICTS OF INTEREST}

The authors declare no conflicts of interest.

\section{REFERENCES}

1. Couser WG, Remuzzi G, Mendis S, Tonelli M. The contribution of chronic kidney disease to the global burden of major noncommunicable diseases. Kidney Int. 2011;80:1258-1270.

2. Bikbov B, Perico N, Remuzzi G. Disparities in chronic kidney disease prevalence among males and females in 195 countries: analysis of the global burden of disease 2016 study. Nephron. 2018;139:313318.

3. Hill NR, Fatoba ST, Oke JL, Hirst JA, O'Callaghan CA, Lasserson DS, Hobbs FD. Global prevalence of chronic kidney disease- a systematic review and meta-analysis. PLoS One. 2016;11:e0158765.

4. Jager KJ, Kovesdy C, Langham R, Rosenberg M, Jha V, Zoccali C. A single number for advocacy and communication-worldwide more than 850 million individuals have kidney diseases. Nephrol Dial Transplant. 2019;34:1803-1805.

5. Kimura T, Isaka Y, Yoshimori T. Autophagy and kidney inflammation. Autophagy. 2017;13:997-1003.

6. Meijer E, Boertien WE, Nauta FL, Bakker SJ, van Oeveren W, Rook $\mathrm{M}$, van der Jagt EJ, van Goor H, Peters DJ, Navis G, de Jong PE, Gansevoort RT. Association of urinary biomarkers with disease severity in patients with autosomal dominant polycystic kidney disease: a cross-sectional analysis. Am J Kidney Dis. 2010;56:883-895.

7. Schrier R, McFann K, Johnson A, Chapman A, Edelstein C, Brosnahan G, Ecder T, Tison L. Cardiac and renal effects of standard versus rigorous blood pressure control in autosomal-dominant polycystic kidney disease: results of a seven-year prospective randomized study. J Am Soc Nephrol. 2002;13:1733-1739.

8. van Dijk MA, Breuning MH, Duiser R, van Es LA, Westendorp RG. No effect of enalapril on progression in autosomal dominant polycystic kidney disease. Nephrol Dial Transplant. 2003;18:2314-2320.

9. Guo C, Xue H, Guo T, Zhang W, Xuan WQ, Ren YT, Wang D, Chen YH, Meng YH, Gao HL, Zhao P. Recombinant human lactoferrin attenuates the progression of hepatosteatosis and hepatocellular death by regulating iron and lipid homeostasis in ob/ob mice. Food Funct. 2020;11:7183-7196.

10. Actor JK, Hwang SA, Kruzel ML. Lactoferrin as a natural immune modulator. Curr Pharm Des. 2009;15:1956-1973.

11. Hegazy R, Salama A, Mansour D, Hassan A. Renoprotective effect of lactoferrin against chromium-induced acute kidney injury in rats: involvement of IL-18 and IGF-1 inhibition. PLoS One. 2016;11:e0151486.

12. Belizi S, Nazarova IA, Klimova IA, Prokof'ev VN, Pushkina NV. Antioxidant properties of lactoferrin from human milk. Bull Exp Biol Med. 1999;127:471-473.

13. Sinopoli A, Isonne C, Santoro MM, Baccolini V. The effects of orally administered lactoferrin in the prevention and management of viral infections: a systematic review. Rev Med Virol. 2021. doi: 10.1002/rmv.2261. [Epub ahead of print]

14. Fernandes KE, Carter DA. The antifungal activity of lactoferrin and its derived peptides: mechanisms of action and synergy with 
drugs against fungal pathogens. Front Microbiol. 2017;8:2.

15. Jenssen H, Hancock RE. Antimicrobial properties of lactoferrin. Biochimie. 2009;91:19-29.

16. Shi P, Liu M, Fan F, Chen H, Yu C, Lu W, Du M. Identification and mechanism of peptides with activity promoting osteoblast proliferation from bovine lactoferrin. Food Biosci. 2018;22:19-25.

17. Qari SH, Attia K. Gene expression of renal lactoferrin and glycemic homeostasis in diabetic rats with reference to the protective role of exogenous bovine lactoferrin. J Basic Appl Zool. 2020;81:12.

18. Hao L, Shan Q, Wei J, Ma F, Sun P. Lactoferrin: major physiological functions and applications. Curr Protein Pept Sci. 2019;20:139-144.

19. Yen CC, Chang WH, Tung MC, Chen HL, Liu HC, Liao CH, Lan YW, Chong KY, Yang SH, Chen CM. Lactoferrin protects hyperoxia-induced lung and kidney systemic inflammation in an in vivo imaging model of NF- $\kappa \mathrm{B} /$ luciferase transgenic mice. Mol Imaging Biol. 2020;22:526-538.

20. Iigo M, Alexander DB, Xu J, Futakuchi M, Suzui M, Kozu T, Akasu T, Saito D, Kakizoe T, Yamauchi K, Abe F, Takase M, Sekine K, Tsuda $\mathrm{H}$. Inhibition of intestinal polyp growth by oral ingestion of bovine lactoferrin and immune cells in the large intestine. Biometals. 2014;27:1017-1029.

21. Chen HL, Yen CC, Wang SM, Tsai TC, Lai ZL, Sun JY, Lin W, Hsu WH, Chen CM. Aerosolized bovine lactoferrin reduces lung injury and fibrosis in mice exposed to hyperoxia. Biometals. 2014;27:10571068 .

22. Ahmed KA, Saikat ASM, Moni A, Kakon SAM, Islam MR, Uddin MJ. Lactoferrin: potential functions, pharmacological insights, and therapeutic promises. J Adv Biotechnol Exp Ther. 2021;4:223-237.

23. Hsu YH, Chiu IJ, Lin YF, Chen YJ, Lee YH, Chiu HW. Lactoferrin contributes a renoprotective effect in acute kidney injury and early renal fibrosis. Pharmaceutics. 2020;12:434.

24. Sørensen M, Sørensen SPL. Comptes Rendus des travaux du Laboratoire Carlsberg. The Proteins in whey. Copenhague: Hagerup in Komm.; 1939. p.3-9.

25. Karav S, German JB, Rouquié C, Le Parc A, Barile D. Studying lactoferrin N-glycosylation. Int J Mol Sci. 2017;18:870.

26. Adlerova L, Bartoskova A, Faldyna M. Lactoferrin: a review. Vet Med. 2008;53:457-468.

27. Furmanski P, Li ZP, Fortuna MB, Swamy CV, Das MR. Multiple molecular forms of human lactoferrin. Identification of a class of lactoferrins that possess ribonuclease activity and lack iron-binding capacity. J Exp Med. 1989;170:415-429.

28. Jiang R, Lopez V, Kelleher SL, Lönnerdal B. Apo- and holo-lactoferrin are both internalized by lactoferrin receptor via clathrinmediated endocytosis but differentially affect ERK-signaling and cell proliferation in Caco-2 cells. J Cell Physiol. 2011;226:3022-3031.

29. Suzuki YA, Lopez V, Lönnerdal B. Mammalian lactoferrin receptors: structure and function. Cell Mol Life Sci. 2005;62:2560-2575.

30. Takayama Y, Aoki R, Uchida R, Tajima A, Aoki-Yoshida A. Role of CXC chemokine receptor type 4 as a lactoferrin receptor. Biochem Cell Biol. 2017;95:57-63.

31. Gao CH, Dong HL, Tai L, Gao XM. Lactoferrin-containing immunocomplexes drive the conversion of human macrophages from M2- into M1-like phenotype. Front Immunol. 2018;9:37.

32. Shin K, Wakabayashi H, Yamauchi K, Yaeshima T, Iwatsuki K. Recombinant human intelectin binds bovine lactoferrin and its peptides. Biol Pharm Bull. 2008;31:1605-1608.
33. Fillebeen C, Descamps L, Dehouck MP, Fenart L, Benaïssa M, Spik G, Cecchelli R, Pierce A. Receptor-mediated transcytosis of lactoferrin through the blood-brain barrier. J Biol Chem. 1999;274:70117017.

34. Rawat P, Kumar S, Sheokand N, Raje CI, Raje M. The multifunctional glycolytic protein glyceraldehyde-3-phosphate dehydrogenase (GAPDH) is a novel macrophage lactoferrin receptor. Biochem Cell Biol. 2012;90:329-338.

35. Milewska A, Zarebski M, Nowak P, Stozek K, Potempa J, Pyrc K. Human coronavirus NL63 utilizes heparan sulfate proteoglycans for attachment to target cells. J Virol. 2014;88:13221-13230.

36. Lang J, Yang N, Deng J, Liu K, Yang P, Zhang G, Jiang C. Inhibition of SARS pseudovirus cell entry by lactoferrin binding to heparan sulfate proteoglycans. PLoS One. 2011;6:e23710.

37. Kanwar JR, Mahidhara G, Roy K, Sasidharan S, Krishnakumar S, Prasad N, Sehgal R, Kanwar RK. Fe-bLf nanoformulation targets survivin to kill colon cancer stem cells and maintains absorption of iron, calcium and zinc. Nanomedicine (Lond). 2015;10:35-55.

38. Gupta I, Sehgal R, Kanwar RK, Punj V, Kanwar JR. Nanocapsules loaded with iron-saturated bovine lactoferrin have antimicrobial therapeutic potential and maintain calcium, zinc and iron metabolism. Nanomedicine (Lond). 2015;10:1289-1314.

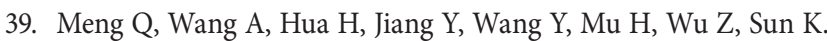
Intranasal delivery of Huperzine $A$ to the brain using lactoferrinconjugated $\mathrm{N}$-trimethylated chitosan surface-modified PLGA nanoparticles for treatment of Alzheimer's disease. Int J Nanomedicine. 2018;13:705-718.

40. Akiyama Y, Oshima K, Kuhara T, Shin K, Abe F, Iwatsuki K, Nadano D, Matsuda T. A lactoferrin-receptor, intelectin 1, affects uptake, sub-cellular localization and release of immunochemically detectable lactoferrin by intestinal epithelial Caco-2 cells. J Biochem. 2013;154:437-448.

41. Kanwar JR, Kamalapuram SK, Krishnakumar S, Kanwar RK. Multimodal iron oxide (Fe3O4)-saturated lactoferrin nanocapsules as nanotheranostics for real-time imaging and breast cancer therapy of claudin-low, triple-negative (ER(-)/PR(-)/HER2(-)). Nanomedicine (Lond). 2016;11:249-268.

42. Ando K, Hasegawa K, Shindo K, Furusawa T, Fujino T, Kikugawa K, Nakano H, Takeuchi O, Akira S, Akiyama T, Gohda J, Inoue J, Hayakawa M. Human lactoferrin activates NF-kappaB through the Toll-like receptor 4 pathway while it interferes with the lipopolysaccharide-stimulated TLR4 signaling. FEBS J. 2010;277:2051-2066.

43. Ronco C, Bellomo R, Kellum JA. Acute kidney injury. Lancet. 2019;394:1949-1964.

44. Basile DP, Anderson MD, Sutton TA. Pathophysiology of acute kidney injury. Compr Physiol. 2012;2:1303-1353.

45. Kimoto Y, Nishinohara M, Sugiyama A, Haruna A, Takeuchi T. Protective effect of lactoferrin on cisplatin-induced nephrotoxicity in rats. J Vet Med Sci. 2013;75:159-164.

46. Okazaki Y, Kono I, Kuriki T, Funahashi S, Fushimi S, Iqbal M, Okada S, Toyokuni S. Bovine lactoferrin ameliorates ferric nitrilotriacetate-induced renal oxidative damage in rats. J Clin Biochem Nutr. 2012;51:84-90.

47. Arab HH, Salama SA, Maghrabi IA. Camel milk ameliorates 5-fluorouracil-induced renal injury in rats: targeting MAPKs, NF- $\mathrm{B}$ and PI3K/Akt/eNOS pathways. Cell Physiol Biochem. 2018;46:16281642. 
48. Li D, Hu Z, He Q, Guo Y, Chong Y, Xu J, Qin L. Lactoferrin alleviates acute alcoholic liver injury by improving redox-stress response capacity in female C57BL/6J mice. J Agric Food Chem. 2021;69:14856-14867.

49. Ammendolia MG, Marchetti M, Superti F. Bovine lactoferrin prevents the entry and intercellular spread of herpes simplex virus type 1 in Green Monkey Kidney cells. Antiviral Res. 2007;76:252-262.

50. Ibuki M, Shoda C, Miwa Y, Ishida A, Tsubota K, Kurihara T. Lactoferrin has a therapeutic effect via HIF inhibition in a murine model of choroidal neovascularization. Front Pharmacol. 2020;11:174.

51. Shimmura S, Shimoyama M, Hojo M, Urayama K, Tsubota K. Reoxygenation injury in a cultured corneal epithelial cell line protected by the uptake of lactoferrin. Invest Ophthalmol Vis Sci. 1998;39:1346-1351.

52. van de Looij Y, Ginet V, Chatagner A, Toulotte A, Somm E, Hüppi PS, Sizonenko SV. Lactoferrin during lactation protects the immature hypoxic-ischemic rat brain. Ann Clin Transl Neurol. 2014;1:955-967.

53. Levey AS, Coresh J. Chronic kidney disease. Lancet. 2012;379:165180.

54. Singh A, Zapata RC, Pezeshki A, Knight CG, Tuor UI, Chelikani PK. Whey protein and its components lactalbumin and lactoferrin affect energy balance and protect against stroke onset and renal damage in salt-loaded, high-fat fed male spontaneously hypertensive stroke-prone rats. J Nutr. 2020;150:763-774.

55. Saito H. Toxico-pharmacological perspective of the Nrf2-Keap1 defense system against oxidative stress in kidney diseases. Biochem Pharmacol. 2013;85:865-872.

56. Burton GJ, Jauniaux E. Oxidative stress. Best Pract Res Clin Obstet Gynaecol. 2011;25:287-299.

57. Betteridge DJ. What is oxidative stress? Metabolism. 2000;49(2 Suppl 1):3-8.

58. Halliwell B. Biochemistry of oxidative stress. Biochem Soc Trans. 2007;35(Pt 5):1147-1150.

59. Sies H. What is oxidative stress? In: Keaney JF, editor. Oxidative stress and vascular disease. Boston: Springer; 2000. p.1-8.

60. Jones DP. Redefining oxidative stress. Antioxid Redox Signal. 2006;8:1865-1879.

61. Ozbek E. Induction of oxidative stress in kidney. Int J Nephrol. 2012;2012:465897.

62. Rojas-Rivera J, Ortiz A, Egido J. Antioxidants in kidney diseases: the impact of bardoxolone methyl. Int J Nephrol. 2012;2012:321714.

63. Finaud J, Lac G, Filaire E. Oxidative stress: relationship with exercise and training. Sports Med. 2006;36:327-358.

64. Taniyama Y, Griendling KK. Reactive oxygen species in the vasculature: molecular and cellular mechanisms. Hypertension. 2003;42:1075-1081.

65. Griendling KK, Sorescu D, Ushio-Fukai M. NAD(P)H oxidase: role in cardiovascular biology and disease. Circ Res. 2000;86:494-501.

66. Kwon G, Uddin MJ, Lee G, Jiang S, Cho A, Lee JH, Lee SR, Bae YS, Moon SH, Lee SJ, Cha DR, Ha H. A novel pan-Nox inhibitor, APX115 , protects kidney injury in streptozotocin-induced diabetic mice: possible role of peroxisomal and mitochondrial biogenesis. Oncotarget. 2017;8:74217-74232.

67. Sureshbabu A, Ryter SW, Choi ME. Oxidative stress and autophagy: crucial modulators of kidney injury. Redox Biol. 2015;4:208-214.

68. Uddin MJ, Kim EH, Hannan MA, Ha H. Pharmacotherapy against oxidative stress in chronic kidney disease: promising small molecule natural products targeting Nrf2-HO-1 signaling. Antioxidants (Basel). 2021;10:258.

69. Modaresi A, Nafar M, Sahraei Z. Oxidative stress in chronic kidney disease. Iran J Kidney Dis. 2015;9:165-179.

70. Kruzel ML, Zimecki M, Actor JK. Lactoferrin in a context of inflammation-induced pathology. Front Immunol. 2017;8:1438.

71. Medzhitov R. Origin and physiological roles of inflammation. Nature. 2008;454:428-435.

72. Nathan C. Points of control in inflammation. Nature. 2002;420:846852.

73. Majno G, Joris I. Cells, tissues, and disease: principles of general pathology. New York: Oxford University Press; 2004.

74. Fan J, Xie K, Wang L, Zheng N, Yu X. Roles of inflammasomes in inflammatory kidney diseases. Mediators Inflamm. 2019;2019:2923072.

75. Ernandez T, Mayadas TN. Immunoregulatory role of TNFalpha in inflammatory kidney diseases. Kidney Int. 2009;76:262-276.

76. Panzer U, Steinmetz OM, Turner JE, Meyer-Schwesinger C, von Ruffer C, Meyer TN, Zahner G, Gómez-Guerrero C, Schmid RM, Helmchen U, Moeckel GW, Wolf G, Stahl RA, Thaiss F. Resolution of renal inflammation: a new role for NF-kappaB1 (p50) in inflammatory kidney diseases. Am J Physiol Renal Physiol. 2009;297:F429F439.

77. Serhan $\mathrm{CN}$. The resolution of inflammation: the devil in the flask and in the details. FASEB J. 2011;25:1441-1448.

78. Drago-Serrano ME, Campos-Rodríguez R, Carrero JC, de la Garza M. Lactoferrin: balancing ups and downs of inflammation due to microbial infections. Int J Mol Sci. 2017;18:501.

79. Abrink M, Larsson E, Gobl A, Hellman L. Expression of lactoferrin in the kidney: implications for innate immunity and iron metabolism. Kidney Int. 2000;57:2004-2010.

80. García-Montoya IA, Cendón TS, Arévalo-Gallegos S, Rascón-Cruz Q. Lactoferrin a multiple bioactive protein: an overview. Biochim Biophys Acta. 2012;1820:226-236.

81. Humphreys BD. Mechanisms of renal fibrosis. Annu Rev Physiol. 2018;80:309-326.

82. Liu Y. Renal fibrosis: new insights into the pathogenesis and therapeutics. Kidney Int. 2006;69:213-217.

83. Jeong BY, Uddin MJ, Park JH, Lee JH, Lee HB, Miyata T, Ha H. Novel plasminogen activator inhibitor-1 inhibitors prevent diabetic kidney injury in a mouse model. PLoS One. 2016;11:e0157012.

84. Liu Y. Cellular and molecular mechanisms of renal fibrosis. Nat Rev Nephrol. 2011;7:684-696.

85. Klahr S, Morrissey J. Obstructive nephropathy and renal fibrosis. Am J Physiol Renal Physiol. 2002;283:F861-F875.

86. Efstratiadis G, Divani M, Katsioulis E, Vergoulas G. Renal fibrosis. Hippokratia. 2009;13:224-229.

87. Wick G, Grundtman C, Mayerl C, Wimpissinger TF, Feichtinger J, Zelger B, Sgonc R, Wolfram D. The immunology of fibrosis. Annu Rev Immunol. 2013;31:107-135.

88. Meng XM, Nikolic-Paterson DJ, Lan HY. Inflammatory processes in renal fibrosis. Nat Rev Nephrol. 2014;10:493-503.

89. Mizushima N. Autophagy: process and function. Genes Dev. 2007;21:2861-2873.

90. Kelekar A. Autophagy. Ann N Y Acad Sci. 2005;1066:259-71.

91. Mariño G, Madeo F, Kroemer G. Autophagy for tissue homeostasis 
and neuroprotection. Curr Opin Cell Biol. 2011;23:198-206.

92. Stern ST, Adiseshaiah PP, Crist RM. Autophagy and lysosomal dysfunction as emerging mechanisms of nanomaterial toxicity. Part Fibre Toxicol. 2012;9:20.

93. White E, DiPaola RS. The double-edged sword of autophagy modulation in cancer. Clin Cancer Res. 2009;15:5308-5316.

94. Brest P, Corcelle EA, Cesaro A, Chargui A, Belaïd A, Klionsky DJ, Vouret-Craviari V, Hebuterne X, Hofman P, Mograbi B. Autophagy and Crohn's disease: at the crossroads of infection, inflammation, immunity, and cancer. Curr Mol Med. 2010;10:486-502.

95. Pan T, Kondo S, Le W, Jankovic J. The role of autophagy-lysosome pathway in neurodegeneration associated with Parkinson's disease. Brain. 2008;131(Pt 8):1969-1978.

96. Kruzel ML, Actor JK, Radak Z, Bacsi A, Saavedra-Molina A, Boldogh I. Lactoferrin decreases LPS-induced mitochondrial dysfunction in cultured cells and in animal endotoxemia model. Innate Immun. 2010;16:67-79.

97. Kimura T, Takabatake Y, Takahashi A, Kaimori JY, Matsui I, Namba T, Kitamura H, Niimura F, Matsusaka T, Soga T, Rakugi H, Isaka Y. Autophagy protects the proximal tubule from degeneration and acute ischemic injury. J Am Soc Nephrol. 2011;22:902-913.

98. Pabla N, Dong Z. Cisplatin nephrotoxicity: mechanisms and renoprotective strategies. Kidney Int. 2008;73:994-1007.

99. Ding Y, Choi ME. Autophagy in diabetic nephropathy. J Endocrinol. 2015;224:R15-R30.

100. Lin TA, Wu VC, Wang CY. Autophagy in chronic kidney diseases. Cells. 2019;8:61.

101. Sohn M, Kim K, Uddin MJ, Lee G, Hwang I, Kang H, Kim H, Lee $\mathrm{JH}, \mathrm{Ha} \mathrm{H}$. Delayed treatment with fenofibrate protects against highfat diet-induced kidney injury in mice: the possible role of AMPK autophagy. Am J Physiol Renal Physiol. 2017;312:F323-F334.

102. Ichimiya T, Yamakawa T, Hirano T, Yokoyama Y, Hayashi Y, Hirayama D, Wagatsuma K, Itoi T, Nakase H. Autophagy and autophagy-related diseases: a review. Int J Mol Sci. 2020;21:8974.

103. Aizawa S, Hoki M, Yamamuro Y. Lactoferrin promotes autophagy via AMP-activated protein kinase activation through low-density lipoprotein receptor-related protein 1. Biochem Biophys Res Commun. 2017;493:509-513.

104. Zhang Y, Zhang ZN, Li N, Zhao LJ, Xue Y, Wu HJ, Hou JM. Nbr1regulated autophagy in Lactoferrin-induced osteoblastic differentiation. Biosci Biotechnol Biochem. 2020;84:1191-1200.

105. Pieczenik SR, Neustadt J. Mitochondrial dysfunction and molecular pathways of disease. Exp Mol Pathol. 2007;83:84-92.

106. Nicolson GL. Mitochondrial dysfunction and chronic disease: treatment with natural supplements. Integr Med (Encinitas). 2014;13:3543.

107. Lowell BB, Shulman GI. Mitochondrial dysfunction and type 2 diabetes. Science. 2005;307:384-387.

108. Kim JA, Wei Y, Sowers JR. Role of mitochondrial dysfunction in insulin resistance. Circ Res. 2008;102:401-414.

109. Madamanchi NR, Runge MS. Mitochondrial dysfunction in atherosclerosis. Circ Res. 2007;100:460-473.

110. Beal MF. Mitochondrial dysfunction in neurodegenerative diseases. Biochim Biophys Acta. 1998;1366:211-223.

111. Ballinger SW. Mitochondrial dysfunction in cardiovascular disease. Free Radic Biol Med. 2005;38:1278-1295.

112. Modica-Napolitano JS, Singh KK. Mitochondrial dysfunction in cancer. Mitochondrion. 2004;4:755-762.

113. Joe Y, Zheng M, Kim HJ, Uddin MJ, Kim SK, Chen Y, Park J, Cho GJ, Ryter SW, Chung HT. Cilostazol attenuates murine hepatic ischemia and reperfusion injury via heme oxygenase-dependent activation of mitochondrial biogenesis. Am J Physiol Gastrointest Liver Physiol. 2015;309:G21-G29.

114. Ratliff BB, Abdulmahdi W, Pawar R, Wolin MS. Oxidant mechanisms in renal injury and disease. Antioxid Redox Signal. 2016;25:119-146.

115. Maekawa H, Inoue T, Ouchi H, Jao TM, Inoue R, Nishi H, Fujii R, Ishidate F, Tanaka T, Tanaka Y, Hirokawa N, Nangaku M, Inagi R. Mitochondrial damage causes inflammation via cGAS-STING signaling in acute kidney injury. Cell Rep. 2019;29:1261-1273.e6.

116. Duann P, Lin PH. Mitochondria damage and kidney disease. $A d v$ Exp Med Biol. 2017;982:529-551.

117. Jiang M, Bai M, Lei J, Xie Y, Xu S, Jia Z, Zhang A. Mitochondrial dysfunction and the AKI-to-CKD transition. Am J Physiol Renal Physiol. 2020;319:F1105-F1116.

118. Wei PZ, Szeto CC. Mitochondrial dysfunction in diabetic kidney disease. Clin Chim Acta. 2019;496:108-116.

119. Güçer S, Talim B, Aşan E, Korkusuz P, Ozen S, Unal S, Kalkanoğlu $\mathrm{SH}$, Kale G, Cağlar M. Focal segmental glomerulosclerosis associated with mitochondrial cytopathy: report of two cases with special emphasis on podocytes. Pediatr Dev Pathol. 2005;8:710-717.

120. Emma F, Montini G, Parikh SM, Salviati L. Mitochondrial dysfunction in inherited renal disease and acute kidney injury. Nat Rev Nephrol. 2016;12:267-280.

121. Park YG, Jeong JK, Lee JH, Lee YJ, Seol JW, Kim SJ, Hur TY, Jung YH, Kang SJ, Park SY. Lactoferrin protects against prion proteininduced cell death in neuronal cells by preventing mitochondrial dysfunction. Int J Mol Med. 2013;31:325-330.

122. Lin JH, Walter P, Yen TS. Endoplasmic reticulum stress in disease pathogenesis. Annu Rev Pathol. 2008;3:399-425.

123. Agostinis P. Endoplasmic reticulum stress. In: Schwab M, editor. Encyclopedia of cancer. Berlin, Heidelberg: Springer Berlin Heidelberg; 2011. p.1240-1244.

124. Hotamisligil GS. Endoplasmic reticulum stress and the inflammatory basis of metabolic disease. Cell. 2010;140:900-917.

125. Xu C, Bailly-Maitre B, Reed JC. Endoplasmic reticulum stress: cell life and death decisions. J Clin Invest. 2005;115:2656-2664.

126. Zheng M, Zhang Q, Joe Y, Kim SK, Uddin MJ, Rhew H, Kim T, Ryter SW, Chung HT. Carbon monoxide-releasing molecules reverse leptin resistance induced by endoplasmic reticulum stress. Am J Physiol Endocrinol Metab. 2013;304:E780-E788.

127. Uddin MJ, Pak ES, Ha H. Carbon monoxide releasing molecule-2 protects mice against acute kidney injury through inhibition of ER stress. Korean J Physiol Pharmacol. 2018;22:567-575.

128. Gallazzini M, Pallet N. Endoplasmic reticulum stress and kidney dysfunction. Biol Cell. 2018;110:205-216.

129. Inagi R. Endoplasmic reticulum stress in the kidney as a novel mediator of kidney injury. Nephron Exp Nephrol. 2009;112:e1-e9.

130. Raghavan S, Malayaperumal S, Mohan V, Balasubramanyam M. A comparative study on the cellular stressors in mesenchymal stem cells (MSCs) and pancreatic $\beta$-cells under hyperglycemic milieu. Mol Cell Biochem. 2021;476:457-469.

131. Jonasch E, Stadler WM, Bukowski RM, Hayes TG, Varadhachary A, Malik R, Figlin RA, Srinivas S. Phase 2 trial of talactoferrin in 
previously treated patients with metastatic renal cell carcinoma. Cancer. 2008;113:72-77.

132. Elzoghby AO, Abdelmoneem MA, Hassanin IA, Abd Elwakil MM, Elnaggar MA, Mokhtar S, Fang JY, Elkhodairy KA. Lactoferrin, a multi-functional glycoprotein: active therapeutic, drug nanocarrier \& targeting ligand. Biomaterials. 2020;263:120355

133. Ishikado A, Imanaka H, Takeuchi T, Harada E, Makino T. Liposomalization of lactoferrin enhanced it's anti-inflammatory effects via oral administration. Biol Pharm Bull. 2005;28:1717-1721.

134. Yao X, Bunt C, Cornish J, Quek SY, Wen J. Oral delivery of lactoferrin: a review. Int J Pept Res Ther. 2013;19:125-134.

135. Knudsen KB, Northeved H, Kumar PE, Permin A, Gjetting T, Andresen TL, Larsen S, Wegener KM, Lykkesfeldt J, Jantzen K, Loft S, Møller P, Roursgaard M. In vivo toxicity of cationic micelles and liposomes. Nanomedicine. 2015;11:467-477.

136. Wei X, Shao B, He Z, Ye T, Luo M, Sang Y, Liang X, Wang W, Luo S, Yang S, Zhang S, Gong C, Gou M, Deng H, Zhao Y, Yang H, Deng S, Zhao C, Yang L, Qian Z, et al. Cationic nanocarriers induce cell necrosis through impairment of $\mathrm{Na}(+) / \mathrm{K}(+)$-ATPase and cause subsequent inflammatory response. Cell Res. 2015;25:237-253.

137. Kato K, Tamaki N, Saito Y, Fujimoto T, Sato A. Amino group PEGylation of bovine lactoferrin by linear polyethylene glycol-pnitrophenyl active esters. Biol Pharm Bull. 2010;33:1253-1255.

138. Nojima Y, Suzuki Y, Yoshida K, Abe F, Shiga T, Takeuchi T, Sugiyama A, Shimizu H, Sato A. Lactoferrin conjugated with 40-kDa branched poly(ethylene glycol) has an improved circulating halflife. Pharm Res. 2009;26:2125-2132.

139. Nojima Y, Suzuki Y, Iguchi K, Shiga T, Iwata A, Fujimoto T, Yoshida K, Shimizu H, Takeuchi T, Sato A. Development of poly(ethylene glycol) conjugated lactoferrin for oral administration. Bioconjug
Chem. 2008;19:2253-2259.

140. Trif M, Guillen C, Vaughan DM, Telfer JM, Brewer JM, Roseanu A, Brock JH. Liposomes as possible carriers for lactoferrin in the local treatment of inflammatory diseases. Exp Biol Med (Maywood). 2001;226:559-564.

141. Roseanu A, Florian PE, Moisei M, Sima LE, Evans RW, Trif M. Liposomalization of lactoferrin enhanced its anti-tumoral effects on melanoma cells. Biometals. 2010;23:485-492.

142. Onishi H, Machida Y, Koyama K. Preparation and in vitro characteristics of lactoferrin-loaded chitosan microparticles. Drug Dev Ind Pharm. 2007;33:641-647.

143. Onishi H, Koyama K, Sakata O, Machida Y. Preparation of chitosan/alginate/calcium complex microparticles loaded with lactoferrin and their efficacy on carrageenan-induced edema in rats. Drug Dev Ind Pharm. 2010;36:879-884.

144. Koyama K, Onishi H, Sakata O, Machida Y. Preparation and in vitro evaluation of chitosan-coated alginate/calcium complex microparticles loaded with fluorescein-labeled lactoferrin. Yakugaku Zasshi. 2009;129:1507-1514.

145. Raei M, Rajabzadeh G, Zibaei S, Jafari SM, Sani AM. Nano-encapsulation of isolated lactoferrin from camel milk by calcium alginate and evaluation of its release. Int J Biol Macromol. 2015;79:669-673.

146. Balcão VM, Costa CI, Matos CM, Moutinho CG, Amorim M, Pintado ME, Gomes AP, Vila MM, Teixeira JA. Nanoencapsulation of bovine lactoferrin for food and biopharmaceutical applications. Food Hydrocoll. 2013;32:425-431.

147. Conesa C, Calvo M, Sánchez L. Recombinant human lactoferrin: a valuable protein for pharmaceutical products and functional foods. Biotechnol Adv. 2010;28:831-838. 